\title{
BMJ open T'ai chi for the treatment of osteoarthritis: a systematic review and meta-analysis
}

\author{
Jung Won Kang, ${ }^{1}$ Myeong Soo Lee, ${ }^{2,3}$ Paul Posadzki, ${ }^{3}$ Edzard Ernst ${ }^{3}$
}

To cite: Kang JW, Lee MS, Posadzki $\mathrm{P}$, et al. T'ai chi for the treatment of osteoarthritis: a systematic review and meta-analysis. BMJ Open 2011;1:e000035 doi:10.1136/bmjopen-2010000035

- Prepublication history for this paper is available online. To view these files please visit the journal online (http:// bmjopen.bmj.com).

Received 15 December 2010 Accepted 17 February 2011

This final article is available for use under the terms of the Creative Commons Attribution Non-Commercial 2.0 Licence; see http://bmjopen.bmj.com

${ }^{1}$ Department of Acupuncture \& Moxibustion, College of Korean Medicine, Kyung Hee University, Seoul, Republic of Korea

${ }^{2}$ Brain Disease Research Centre, Korea Institute of Oriental Medicine, Daejeon, South Korea

${ }^{3}$ Complementary Medicine, Peninsula Medical School, University of Exeter, Exeter, UK

Correspondence to Dr Myeong Soo Lee; drmslee@gmail.com

\section{ABSTRACT}

Objectives: To summarise and critically evaluate the evidence from randomised clinical trials (RCTs) of t'ai chi as a treatment for patients with osteoarthritis $(O A)$. Design: Eleven databases were searched from their inception to July 2010. RCTs testing t'ai chi against any type of controls in human patients with $\mathrm{OA}$ localised in any joints that assessed any type of clinical outcome measures were considered. Two reviewers independently performed the selection of the studies, data abstraction and validations. The risk of bias was assessed using Cochrane criteria.

Results: Nine RCTs met the inclusion criteria, and most of them had significant methodological weaknesses. Six RCTs tested the effects of t'ai chi compared with that of an attention-control programme, a waiting list and routine care or self-help programmes in patients with $\mathrm{OA}$ in the knee. The meta-analysis suggested that t'ai chi has favourable effects on pain ( $\mathrm{n}=256$; standard mean difference (SMD), $-0.79 ; 95 \% \mathrm{Cl}-1.19$ to $-0.39 ; \mathrm{p}=0.0001$; $\mathrm{I}^{2}=55 \%$ ), physical function $(\mathrm{n}=256$; SMD,-0.86 ; $95 \% \mathrm{Cl}-1.20$ to $-0.52 ; p<0.00001 ; \mathrm{I}^{2}=38 \%$ ) and joint stiffness $(n=256$; SMD, $-0.53 ; 95 \% \mathrm{Cl}-0.99$ to $\left.-0.08 ; p=0.02 ; 1^{2}=67 \%\right)$.

Conclusion: The results are encouraging and suggest that t'ai chi may be effective in controlling pain and improving physical function in patients with $\mathrm{OA}$ in the knee. However, owing to the small number of RCTs with a low risk of bias, the evidence that t'ai chi is effective in patients with $O A$ is limited.

\section{INTRODUCTION}

Osteoarthritis (OA) is the most common degenerative joint disease and affects the knees, hips, hands and spine. It is characterised by degradation of the joints, including cartilage surfaces and subchondral bone, causing joint-space narrowing, pain, stiffness, swelling, tenderness and reduced physical function. ${ }^{12}$ Approximately $5 \%$ and $10 \%$ of adults aged 60 years or older suffer from OA of the hip ${ }^{1}$ and knee, ${ }^{2}$ respectively. Because there is no known cure for OA, the main therapeutic strategy is symptomatic. Treatment includes analgesics, non-steroidal

\section{ARTICLE SUMMARY}

Article focus

- T'ai chi is a form of physical exercise that may offer physiological and psychological benefits to osteoarthritis sufferers.

Key messages

n This systematic review offers limited evidence suggesting that t'ai chi may be effective for controlling pain and improving physical function in patients with osteoarthritis in the knee.

Strengths and limitations of this study

- The strength of this systematic review is its extensive, unbiased search of various databases without language restriction.

- Our systematic review pertains to the potential incompleteness of the evidence reviewed including publication and location bias, poor quality of the primary data and poor reporting of results.

anti-inflammatory drugs, COX-2 inhibitors, glucocorticoids, topical analgesics and cartilage protective agents (eg, diacerein, glucosamine and chondroitin). Exercise is often recommended for managing $\mathrm{OA},{ }^{3-5}$ and there is some evidence of its effectiveness. ${ }^{267}$ However, total hip or knee replacements may often be the most effective treatments. ${ }^{12}$

T'ai chi is a form of complementary therapy with similarities to aerobic exercise that involves relaxation, deep breathing techniques and slow movements. ${ }^{8}$ There are two systematic reviews of t'ai chi for $\mathrm{OA}^{9}$ or musculoskeletal pain. ${ }^{10}$ One of them included five randomised clinical trials (RCTs) and seven controlled clinical trials compared with several types of controls. This review suggested that TC may be beneficial for pain control in patients with knee OA, although the review is outdated..$^{9}$ Recently, another review was published in 2009 that was based on the same four RCTs for OA as well as one RCT for arthritis, one RCT for tension headache and one RCT for 
rheumatoid arthritis. ${ }^{10}$ This review also showed some favourable effects of t'ai chi for musculoskeletal pain, although the authors pooled the trials regardless of clinical heterogeneity, and the review is also now outdated.

Therefore, the aim of this article was to update, complete and critically evaluate the evidence from RCTs of t'ai chi as a method of treatment for patients with OA of any joint.

\section{METHODS}

\section{Searching}

Electronic databases were explored from their respective inceptions to July 2010; MEDLINE, AMED, EMBASE, CINAHL, five Korean Medical Databases (Korean Studies Information, DBPIA, Korea Institute of Science and Technology Information, KoreaMed, and Research Information Service System), Chinese Medical Databases (China National Knowledge Infrastructure: CNKI) and the Cochrane Library. The search strategies are shown in supplement 1. In addition, our own departmental files were manually searched. The references of all located articles and the proceedings of the First International Conference of T'ai chi for Health (December 2006, Seoul, South Korea) were also hand-searched for further relevant articles. No restrictions on years or publication status were imposed. We did not publish the protocol in advance.

\section{Selection}

All prospective RCTs of t'ai chi for OA were included without restrictions based on joint location (eg, chronic pain of the knee, hip or back). Trials comparing t'ai chi with any type of control intervention were also included, as were dissertations and abstracts. Any trials with t'ai chi as part of a complex intervention were excluded.

\section{Data abstraction and study characteristics}

Hard copies of all articles were obtained and read in full by two independent reviewers (MSL and JWK). The data from these articles were validated and abstracted according to predefined criteria that included the author information, the country of origin of the study, the sample size, the age of the participants, the site and duration of OA, the regimen of the experimental and control interventions, the main outcome, the associated adverse events and the author's conclusion (table 1).

\section{Validity assessment}

The risk of bias was assessed using the Cochrane classification with four criteria: sequence generation, allocation concealment, blinding and incomplete outcome measurement. ${ }^{20}$ A low risk of bias for assessor blinding was assumed if specified in the text regardless of the type of outcome measures (even for self-reported outcome measures). We assumed that the assessor was the person in charge of managing the outcome measures. Disagreements were resolved by discussions between the reviewers (MSL and JWK).
Quantitative data synthesis

Because there was no important clinical heterogeneity, we synthesised the results in a meta-analysis. The mean change in outcome measures between the end of the final intervention (post-treatment) and the baseline was used to assess the differences between intervention and control groups. Standardised mean differences (SMDs) were used because the studies measured the outcomes on different scales (WOMAC and VAS). SMDs and 95\% CIs were calculated using Cochrane Collaboration software (Review Manager Version 5.0 for Windows; Copenhagen: The Nordic Cochrane Centre). For studies with insufficient information, we contacted the primary authors to acquire and verify data when possible. For one trial, ${ }^{13}$ we contacted the authors to check the SDs of the original raw data because they reported the same SDs for the t'ai chi and control groups. The original authors clarified that the reported values did not differ from the raw data. Summary estimates of the treatment effect were calculated using the random effects model to account for expected heterogeneity. Differences between the treatment groups and the control groups were considered relevant in the context of this study. For one trial, ${ }^{12}$ the author did not report the SD of changes for any outcomes. We therefore used the pre- and posttreatment means and the SDs for each group, and assumed a conservative within-subject pre-test-post-test correlation of $0.5^{21}$ to calculate the SDs of change in each group using the methods in the Cochrane Handbook for Systematic Reviews of Interventions. ${ }^{22}$ Cochrane's Q test and $\mathrm{I}^{2}$ were used to assess statistical heterogeneity. We determined that there was considerable heterogeneity when Cochrane's $Q$ test result was determined with $\mathrm{p}<0.10$, and $\mathrm{I}^{2}$ was above $75 \%$. If a sufficient number of studies (at least 10 studies) were available, we attempted to assess publication bias using a funnel plot or Egger's regression test, whereby effect estimates of the common outcome measures were plotted against the sample size. ${ }^{23} 24$

\section{RESULTS}

\section{Trial flow and study characteristics}

The literature search revealed 117 articles, of which 108 studies were excluded. The reasons for article exclusion during the selection process are described in figure 1 . Key data regarding the nine included RCTs are summarised in table $1 .{ }^{11-19}$ A total of 521 participants were included in these trials. Four RCTs originated in the USA, ${ }^{12} 131819$ three RCTs were from Korea, ${ }^{14-16}$ one RCT was from China, ${ }^{11}$ and one RCT was from Australia. ${ }^{17}$ Six RCTs included patients with knee $\mathrm{OA},{ }^{11-16}$ while the other three RCTs included patients with hip, knee or multiple-joint OA. ${ }^{17-19}$ Yang-style t'ai chi was used in four trials, ${ }^{11-13}{ }^{18}$ Sun-style was used in three trials, ${ }^{15-17} \mathrm{Wu}$-style was used in one trial, ${ }^{19}$ and one trial did not report the style of t'ai chi used. ${ }^{14}$ All RCTs had a parallel-group design.

Most trials had a relatively small sample size, and only five trials were based on a sample size 


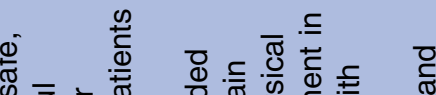

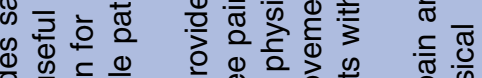

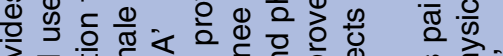

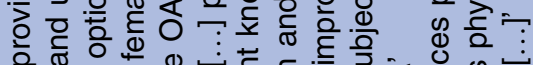

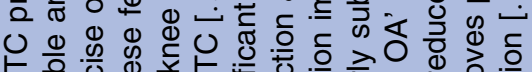
은 응

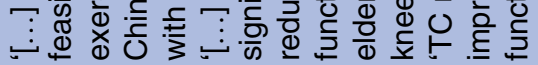

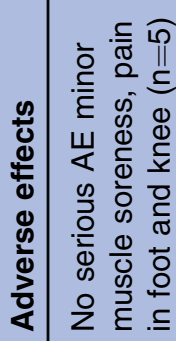

क

ฮั

잉

टी

흐

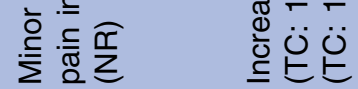

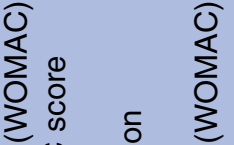

Oृ:

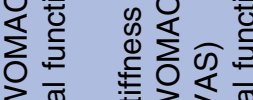

¿ ত্তে

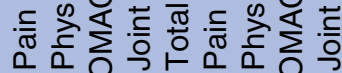

Eิญ

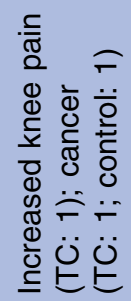

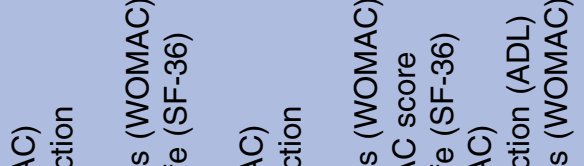

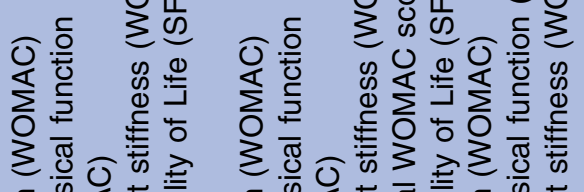

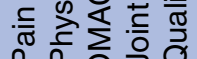

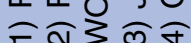

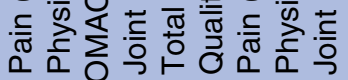

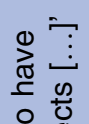

का

ฮั $\frac{\pi}{2}$

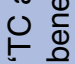

Еญญ

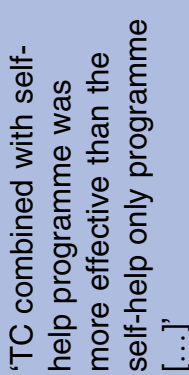

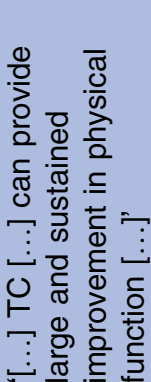

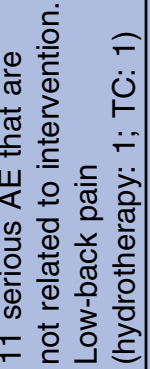

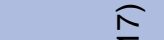

을

กิ

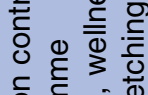

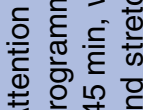

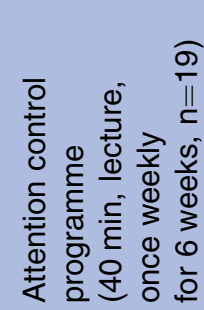

कิ

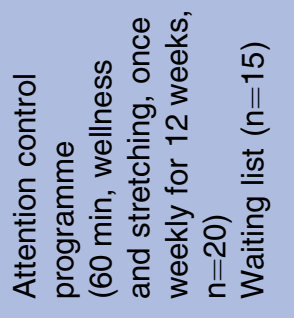

ㄷํำ

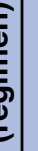

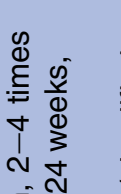

\section{(2) \\ $\frac{0}{2} \frac{1}{0}$}

है

줄

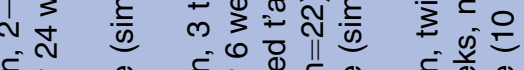

宅 节

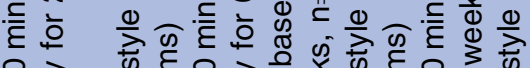

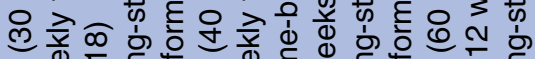

产

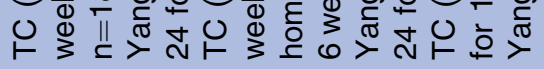

들

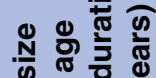

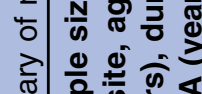

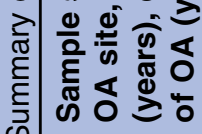

क

ஜृ

लृ

นก กิ

음

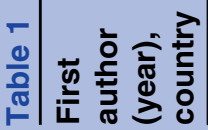
ó

$\frac{\sqrt{2}}{\bar{z}} \frac{\pi}{\overline{0}}$

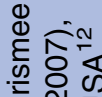

\begin{tabular}{ll}
$\infty$ \\
\hdashline
\end{tabular}

$\frac{\overrightarrow{\mathrm{v}}}{\mathrm{d}}$

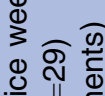

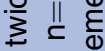

है

Q $\sum_{\infty}^{\infty} \stackrel{\infty}{=}$

난

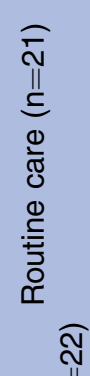

है

흉 등

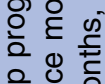

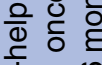

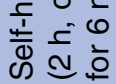

$\sum_{\substack{0 \\ \vdots}}^{0}$

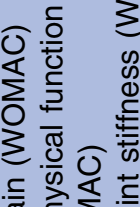

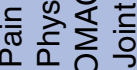

โิญํำ 

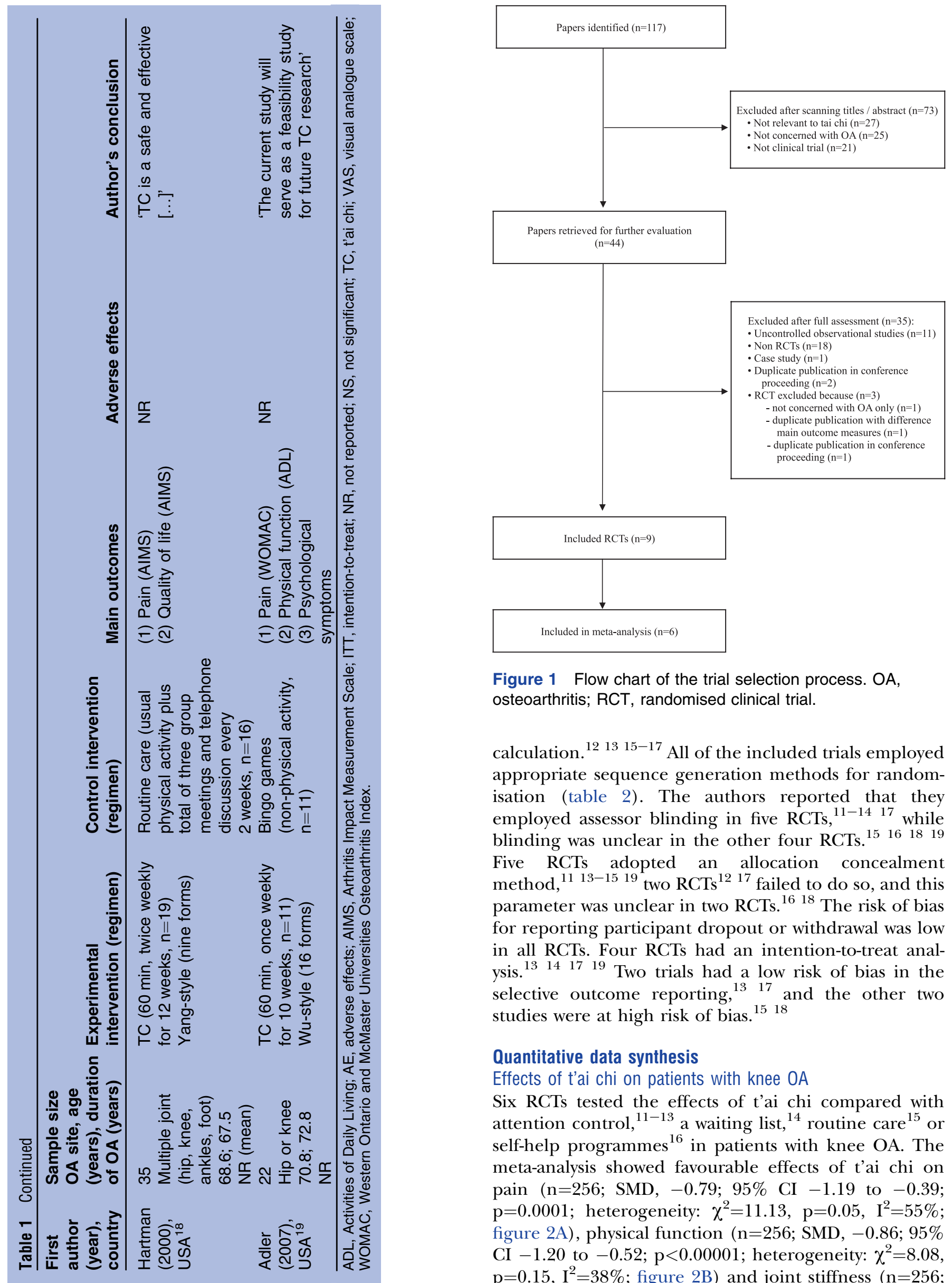

Figure 1 Flow chart of the trial selection process. OA, osteoarthritis; RCT, randomised clinical trial.

calculation. ${ }^{12}{ }^{13}{ }^{15-17}$ All of the included trials employed appropriate sequence generation methods for randomisation (table 2). The authors reported that they employed assessor blinding in five RCTs, ${ }^{11-14}{ }^{17}$ while blinding was unclear in the other four RCTs. ${ }^{15} 161819$ Five RCTs adopted an allocation concealment method, ${ }^{11}{ }^{13-1519}$ two RCTs $^{12}{ }^{17}$ failed to do so, and this parameter was unclear in two RCTs. ${ }^{16} 18$ The risk of bias for reporting participant dropout or withdrawal was low in all RCTs. Four RCTs had an intention-to-treat analysis. ${ }^{13} 14 \quad 17 \quad 19$ Two trials had a low risk of bias in the selective outcome reporting, ${ }^{13} 17$ and the other two studies were at high risk of bias. ${ }^{15} 18$

\section{Quantitative data synthesis}

Effects of t'ai chi on patients with knee $0 \mathrm{~A}$

Six RCTs tested the effects of t'ai chi compared with attention control, ${ }^{11-13}$ a waiting list, ${ }^{14}$ routine care ${ }^{15}$ or self-help programmes ${ }^{16}$ in patients with knee OA. The meta-analysis showed favourable effects of t'ai chi on pain $(\mathrm{n}=256$; SMD, $-0.79 ; 95 \%$ CI -1.19 to -0.39 ; $\mathrm{p}=0.0001$; heterogeneity: $\chi^{2}=11.13, \mathrm{p}=0.05, \mathrm{I}^{2}=55 \%$; figure $2 A)$, physical function $(n=256$; SMD,-0.86 ; $95 \%$ CI -1.20 to $-0.52 ; \mathrm{p}<0.00001$; heterogeneity: $\chi^{2}=8.08$, $\mathrm{p}=0.15, \mathrm{I}^{2}=38 \%$; figure $\left.2 \mathrm{~B}\right)$ and joint stiffness $(\mathrm{n}=256$; 
Table 2 Risk of bias of included randomised controlled trials*

\begin{tabular}{|c|c|c|c|c|c|c|c|}
\hline $\begin{array}{l}\text { Study: first author } \\
\text { (year) }\end{array}$ & $\begin{array}{l}\text { Random } \\
\text { sequence } \\
\text { generation }\end{array}$ & $\begin{array}{l}\text { Allocation } \\
\text { concealment }\end{array}$ & $\begin{array}{l}\text { Patient } \\
\text { blinding }\end{array}$ & $\begin{array}{l}\text { Assessor } \\
\text { blinding }\end{array}$ & $\begin{array}{l}\text { Reporting } \\
\text { drop-out or } \\
\text { withdrawal } \dagger\end{array}$ & $\begin{array}{l}\text { Intention- } \\
\text { to-treat } \\
\text { analysis } †\end{array}$ & $\begin{array}{l}\text { Selective } \\
\text { outcome } \\
\text { reporting }\end{array}$ \\
\hline $\mathrm{Ni}(2010)^{11}$ & $\mathrm{~L}$ & $\mathrm{~L}$ & $\mathrm{H}$ & $\mathrm{L}$ & $\mathrm{L}$ & $\mathrm{H}$ & $U$ \\
\hline Brismee $(2007)^{12}$ & $\mathrm{~L}$ & $\mathrm{H}$ & $\mathrm{H}$ & $\mathrm{L}$ & $\mathrm{L}$ & $\mathrm{H}$ & $U$ \\
\hline Wang $(2009)^{13}$ & $\mathrm{~L}$ & $\mathrm{~L}$ & $\mathrm{H}$ & $\mathrm{L}$ & $\mathrm{L}$ & $\mathrm{L}$ & $\mathrm{L}$ \\
\hline Lee $(2009)^{14}$ & $\mathrm{~L}$ & $\mathrm{~L}$ & $\mathrm{H}$ & $\mathrm{L}$ & $\mathrm{L}$ & $\mathrm{L}$ & $U$ \\
\hline Song $(2003)^{15}$ & $\mathrm{~L}$ & $\mathrm{~L}$ & $\mathrm{H}$ & $U$ & $\mathrm{~L}$ & $\mathrm{H}$ & $\mathrm{H}$ \\
\hline Song $(2009)^{16}$ & $\mathrm{~L}$ & U & $\mathrm{H}$ & $U$ & $\mathrm{~L}$ & $\mathrm{H}$ & $U$ \\
\hline Fransen $(2007)^{17}$ & $\mathrm{~L}$ & $\mathrm{H}$ & $\mathrm{H}$ & $\mathrm{L}$ & $\mathrm{L}$ & $\mathrm{L}$ & $\mathrm{L}$ \\
\hline Hartman $(2000)^{18}$ & $\mathrm{~L}$ & $U$ & $\mathrm{H}$ & $U$ & $\mathrm{~L}$ & $\mathrm{H}$ & $\mathrm{H}$ \\
\hline Adler $(2007)^{19}$ & $\mathrm{~L}$ & $\mathrm{~L}$ & $\mathrm{H}$ & $U$ & $\mathrm{~L}$ & $\mathrm{~L}$ & $\mathrm{U}$ \\
\hline
\end{tabular}

SMD, $-0.53 ; 95 \%$ CI -0.99 to $-0.08 ; \mathrm{p}=0.02$; heterogeneity: $\chi^{2}=15.28, \mathrm{p}=0.009, \mathrm{I}^{2}=67 \%$; figure $2 \mathrm{C}$ ). A subanalysis was performed to explore whether heterogeneity could be partially explained by the type of control intervention.

\section{T'ai chi versus attention control}

Three RCTs ${ }^{11-13}$ compared the effects of t'ai chi on pain, physical function and joint stiffness with attention control in patients with knee OA. All trials reported favourable effects of t'ai chi on pain reduction. The meta-analysis also showed superior effects of t'ai chi for pain reduction compared with attention control $(\mathrm{n}=100 ; \mathrm{SMD},-1.18 ; 95 \% \mathrm{CI}-1.82$ to $-0.54 ; \mathrm{p}=0.0003$; heterogeneity: $\chi^{2}=4.28, p=0.12, \mathrm{I}^{2}=53 \%$; figure $2 \mathrm{~A}$ ).

Two ${ }^{1113}$ out of three RCTs ${ }^{11-13}$ showed favourable effects. The meta-analysis showed the favourable effects of t'ai chi on physical function compared with attention control $(\mathrm{n}=100$; SMD, $-1.20 ; 95 \%$ CI -1.74 to $-0.67 ; \mathrm{p}<0.0001$; heterogeneity: $\chi^{2}=2.99, \mathrm{p}=0.22, \mathrm{I}^{2}=33 \%$; figure $2 \mathrm{~B}$ ).

Three RCTs assessed the effects of t'ai chi on joint stiffness compared with attention control, ${ }^{11-13}$ but only one of the three trials reported favourable effects. ${ }^{11}$ The meta-analysis did not show any positive effects of t'ai chi $(n=100 ;$ SMD, $-0.82 ; 95 \%$ CI -1.67 to 0.04 ; $\mathrm{p}=0.06 ;$ heterogeneity: $\chi^{2}=8.03, \mathrm{p}=0.02, \quad \mathrm{I}^{2}=75 \%$; figure 2C).

One RCT compared the effect of t'ai chi on the quality of life compared with attention control, but it failed to show any favourable effect on this condition. ${ }^{13}$

\section{T'ai chi versus routine treatments, a waiting list or a self-help programme}

Three RCTs assessed the effectiveness of t'ai chi on pain caused by knee OA compared with routine treatments, a waiting list or a self-help programme. ${ }^{14-16}$ Two RCTs suggested a significant pain reduction compared with the waiting control ${ }^{14}$ and the routine treatments, ${ }^{15}$ while the other RCT did not. ${ }^{16}$ The meta-analysis showed favourable effects of t'ai chi on pain reduction $(\mathrm{n}=156$; SMD, $-0.47 ; 95 \% \mathrm{CI}-0.79$ to $-0.14 ; \mathrm{p}=0.005$; heterogeneity: $\chi^{2}=0.96, \mathrm{p}=0.62, \mathrm{I}^{2}=0 \%$; figure $2 \mathrm{~A}$ ).
Three RCTs tested the effect of t'ai chi on physical function compared with routine treatments, a waiting list or a self-help programme. ${ }^{14-16}$ Two RCTs showed significantly favourable effects, ${ }^{15} 16$ while the other trial did not. ${ }^{14}$ The meta-analysis showed superior effects of t'ai chi on physical function compared with routine cares $(\mathrm{n}=156 ; \mathrm{SMD},-0.60 ; 95 \% \mathrm{CI}-0.93$ to $-0.28 ; \mathrm{p}=0.0003$; heterogeneity: $\chi^{2}=0.79, \mathrm{p}=0.67, \mathrm{I}^{2}=0 \%$; figure $2 \mathrm{~B}$ ).

Three RCTs assessed the effects of t'ai chi on joint stiffness compared with routine treatments, a waiting list or a self-help programme. ${ }^{14-16}$ One RCT showed significantly favourable effects of t'ai chi, ${ }^{15}$ while two trials did not. ${ }^{1416}$ The meta-analysis did not show any significant effects of t'ai chi on joint stiffness $(n=156$; SMD, -0.30 ; $95 \%$ CI -0.79 to $0.19 ; \mathrm{p}=0.23$; heterogeneity: $\chi^{2}=4.39$, $\mathrm{p}=0.11, \mathrm{I}^{2}=54 \%$; figure $2 \mathrm{C}$ ).

\section{Effects of t'ai chi in patients with multiple-joint $0 \mathrm{~A}$}

Three RCTs tested the effects of t'ai chi compared with hydrotherapy, a waiting list, routine treatments or participation in bingo games in patients with multiple joint OA. ${ }^{17-19}$ One RCT with three parallel groups failed to show any superior effects of t'ai chi on pain reduction, physical function and quality of life when compared with hydrotherapy or a waiting-list control group but did show improved physical function when compared with the waiting-list control group. ${ }^{17}$ The second RCT showed favourable effects of t'ai chi on the quality of life, compared with routine treatments, but not on pain reduction. ${ }^{18}$ The third RCT did not show any significant differences in pain reduction, physical function or joint stiffness between t'ai chi and participation in bingo games. ${ }^{19}$

\section{Adverse effects}

Four RCTs ${ }^{11-13} 17$ assessed adverse effects, while the other five RCTs ${ }^{14-161819}$ did not. None of the four RCTs reported any serious adverse effects. Two RCTs reported minor muscle soreness and foot and knee pain in the early days of intervention. ${ }^{11} 12$ One RCT reported increased knee pain and two cancer occurrences that 
Figure 2 Forest plot of the effects of t'ai chi (TC) on (A) pain, (B) physical function and (C) joint stiffness in patients with knee osteoarthritis

(A) Pain

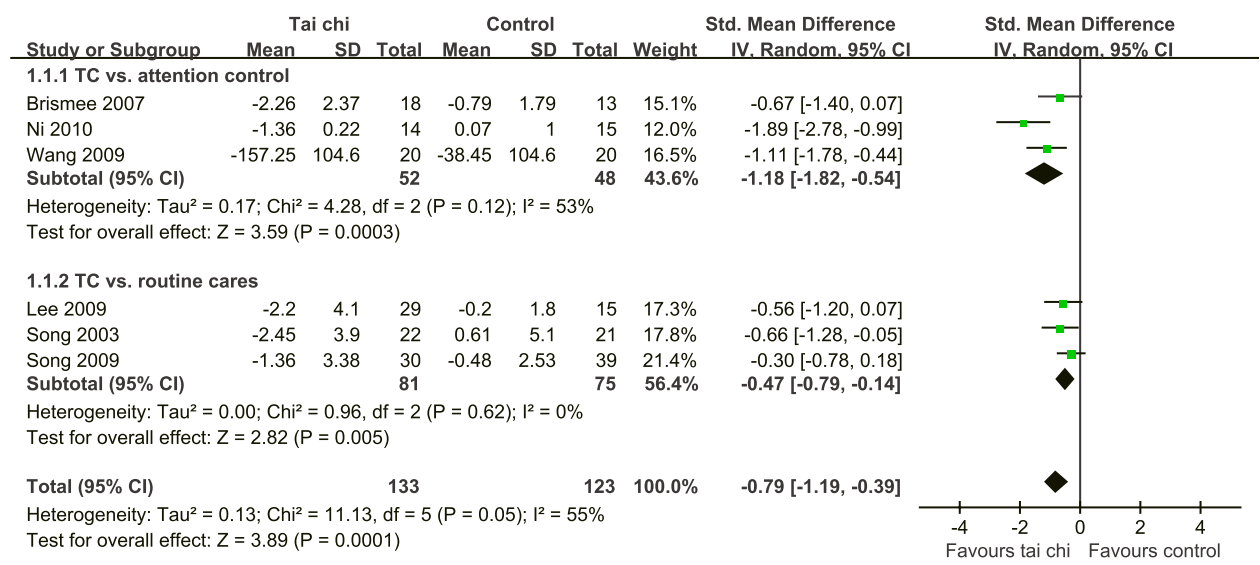

\section{(B) Physical function}

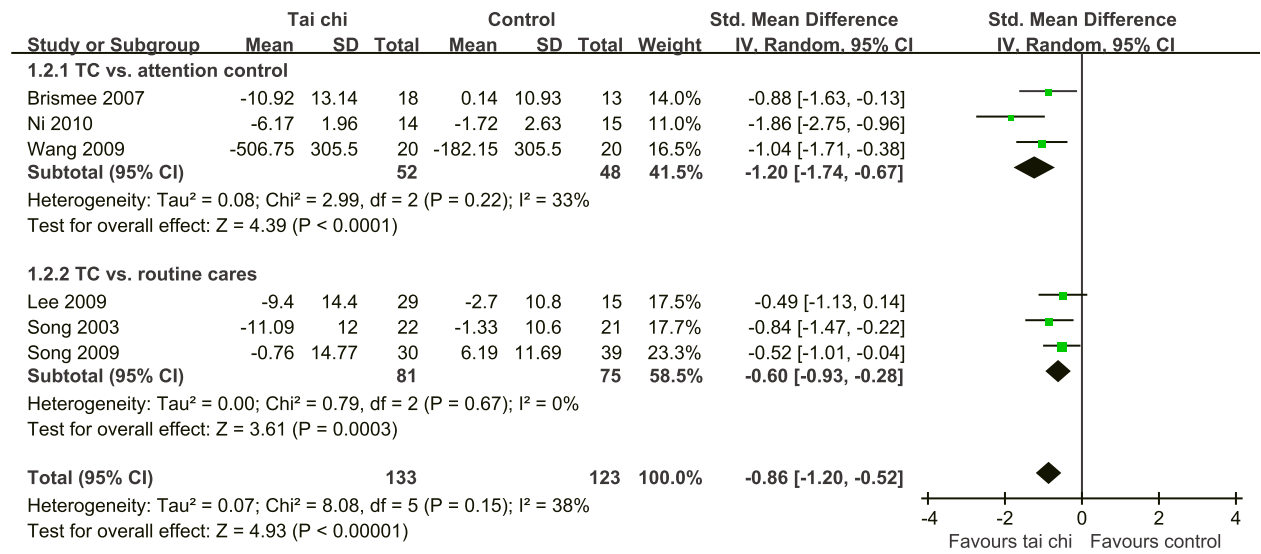

\section{(C) Stiffness}

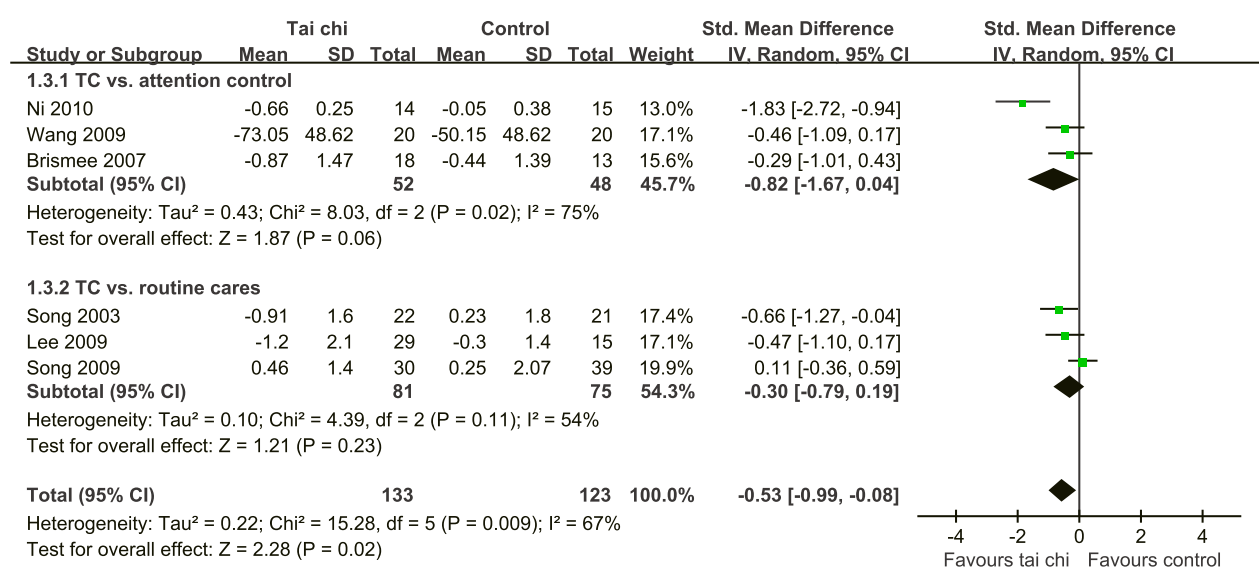

were not related to the interventions. ${ }^{13}$ The other RCT reported serious adverse effects that were not related to the intervention. ${ }^{17}$

\section{DISCUSSION}

Overall, this systematic review suggests that t'ai chi may be an effective treatment for pain and physical function associated with knee OA, compared with attention control or routine care. However, several caveats must be considered. For joint stiffness, the evidence was not robust, and for a mixed population with hip or knee OA, the evidence is not sufficient to conclude whether t'ai chi was beneficial.

Our review aimed to update and complete the evidence by adding recent RCTs of t'ai chi as a method of treatment in patients with OA. Compared with two previous reviews, ${ }^{910}$ we identified four new RCTs with a low risk of bias ${ }^{11}{ }^{13-15}$ and successfully updated the evidence for therapy. The results of our review are similar to the other two reviews. ${ }^{10}{ }^{14}$ One previous 
review ${ }^{14}$ showed that t'ai chi may be beneficial for pain control in patients with knee OA, while the other review ${ }^{10}$ also reported some favourable effects of t'ai chi for musculoskeletal pain. However, both reviews expressed concern regarding the poor methodological quality of the included primary studies.

Previous systematic reviews have suggested that there are clinically important differences among various therapies, compared with various control groups, in OA pain reduction and functional improvement. ${ }^{2}$ The effect size of the pain reduction and the functional improvement in our review was higher than exercise, non-steroidal anti-inflammatory drugs and drug therapy; this effect is clinically significant. ${ }^{2}$ However, these results are difficult to compare quantitatively owing to the use of different assessment measures for evaluating pain and the use of different controls for evaluating the comparisons.

Limitations of this study include the potential incompleteness of the evidence reviewed. The distorting effects of publication and location bias on systematic reviews and meta-analyses are well documented..$^{25-27}$ We are confident that our search strategy located all relevant data; however, some degree of uncertainty remains. Another possible source of bias is the fact that half of the included trials were performed in China and Korea, where apparently no negative studies have been reported. ${ }^{28}$ Our review may be affected by the potentially poor quality of the primary data and poor reporting of results, which were highly heterogeneous in virtually every respect.

The risk of bias in the studies was assessed based on the descriptions of sequence generation, allocation concealment, blinding, incomplete outcome measures and selective outcome reporting. Based on these assessments, the risk of bias varied across the included studies. Only three RCTs had a low risk of bias, ${ }^{13} 1417$ and two studies had a moderate risk of bias. ${ }^{11} 19$ The other four RCTs were at high risk of being biased. ${ }^{12} 151618$ Five RCTs employed allocation concealment, ${ }^{11} 13141619$ and four RCTs used an intention-to-treat analysis. ${ }^{13} 141719$ Inappropriate allocation concealment and the lack of blinding exaggerate the results of outcome measures. ${ }^{29} 30$ Only two RCTs were at low risk of bias in selective outcome reporting. ${ }^{13}{ }^{17}$ Even though the authors reported that they employed assessor blinding, ${ }^{11-14} 17$ some outcomes that they measured relied on the patient's subjective reporting, and so the patient's and assessor's blinding becomes unachievable and irrelevant. The main limitations of the included studies were small sample sizes, the inadequate control for non-specific effects and a lack of power calculations or adequate follow-up. Additionally, the fact that t'ai chi interventions cannot control for placebo effects limits generalisability. Second, adequate follow-ups of 6-12 months are advisable for future studies of t'ai chi for OA.

One could argue that the employment of the Cochrane risk-of-bias tool to assess the methodological bias in the clinical trial is not acceptable. This tool was recently recommended for assessing methodological quality in lieu of other scoring assessment tools, such as the Jadad scale. ${ }^{20}$ It has been proposed that using a quality score for clinical trials is not adequate. ${ }^{31} 32$ Although the inter-rater disagreements across the domains were reported in the Cochrane risk-of-bias tool, their overall reliability was fair. ${ }^{33}$ We also calculated our reliability for nine included trials with the Excel module (http://agreestat.com/agreestat.html). Our inter-rater agreement for the individual domains of the risk-of-bias tool to nine included trials ranged from substantial to almost perfect $(0.88$ for random sequence generation; 0.70 for allocation concealment; 1.00 for patient blinding; 0.85 for assessor blinding; 0.88 for reporting drop-out or withdrawal; 0.69 or intention-totreat analysis; and 0.71 for selective outcome reporting). Therefore, the Cochrane risk-of-bias tool may be the most comprehensive tool with fair reliability that is currently available.

Proponents of t'ai chi claim that it improves flexibility, strength and balance, especially in older people. Clearly, these claims need to be tested. The pooled results from six RCTs ${ }^{11-16}$ suggested that pain intensity was reduced when patients used t'ai chi, compared with attention control or routine care for knee OA. However, three RCTs found that t'ai chi had no significant effect on pain reduction when compared with hydrotherapy, waiting list, routine treatments or participation in bingo games in multiple joint OA. ${ }^{17-19}$ These results may be explained, in part, through inadequate blinding and control for non-specific effects in some of the positive studies, among other sources of bias.

Assuming that t'ai chi was beneficial for treating OA, the possible mechanisms of action may be of interest. Regular t'ai chi has been postulated to improve balance and reduce the likelihood of falls by improving muscle flexibility and trunk rotation. T'ai chi is a form of physical exercise combined with relaxation. Physical movement in t'ai chi can improve joint stability and aid in reducing excess weight, effectively decreasing joint pain, increasing function and reducing the advancement of OA. ${ }^{35} 36$ Furthermore, t'ai chi may also influence the psychosocial quality of life, which may have a positive influence on chronic pain. ${ }^{35} 37$ The question of whether t'ai chi is superior to other forms of therapeutic exercise is currently unanswered and is thus a topic for further investigation.

Four of the reviewed studies reported minor adverse events related to t'ai chi. ${ }^{11-13} 17$ T'ai chi appears to be generally safe, and serious adverse effects have not been reported. However, adverse effects were not the focus of this review and may require further research.

Future RCTs of t'ai chi for OA should adhere to accepted standards of trial methodology. The studies included in this review show a number of problems that have been noted by other reviews of trials examining the efficacy of t'ai chi, such as the expertise of t'ai chi practitioners, the pluralism of t'ai chi, the frequency and duration of treatment, the use of validated primary 
outcome measures and adequate statistical tests, and heterogeneous comparison groups. ${ }^{38} 39$ Furthermore, even though it is difficult to blind subjects to treatment, employing assessor blinding and allocation concealment are important for reducing bias. A clinical study is only truly useful if the intervention used can be replicated; hence, the type of t'ai chi employed is important. There are significant differences between the numerous forms of t'ai chi, and a clear description of the t'ai chi intervention should be provided together with a description of the level of expertise of the instructors.

In conclusion, there are encouraging results suggesting that t'ai chi may be effective in controlling pain and improving physical function in patients with knee OA. However, owing to the number of eligible RCTs and the often-poor quality of the available RCTs, the evidence is limited.

Funding MSL was supported by Korea Institute of Oriental Medicine (K10251 and K11111).

Competing interests None.

Contributors JWK and MSL designed the review, performed searches, appraised and selected trials, abstracted data, contacted authors for additional data, carried out the analysis and interpretation of the data, and drafted this report. PP and EE reviewed and critiqued the review protocol and this report, and assisted in designing the review. All authors read and approved the final version of the manuscript.

Provenance and peer review Not commissioned; externally peer reviewed.

Data sharing statement No additional data available.

\section{REFERENCES}

1. Scott D. Osteoarthritis of the hip. Clin Evid 2009;06:1122.

2. Scott D, Kowalczyk A. Osteoarthritis of the knee. Clin Evid 2007;12:1121.

3. American College of Rheumatology Subcommittee on Osteoarthritis Guidelines. Recommendations for the medical management of osteoarthritis of the hip and knee: 2000 update. Arthritis Rheum 2000;43:1905-15.

4. Jordan KM, Arden NK, Doherty M, et al. EULAR Recommendations 2003: an evidence based approach to the management of knee osteoarthritis: Report of a Task Force of the Standing Committee for International Clinical Studies Including Therapeutic Trials (ESCISIT). Ann Rheum Dis 2003;62:1145-55.

5. Scott DL, Shipley M, Dawson A, et al. The clinical management of rheumatoid arthritis and osteoarthritis: strategies for improving clinical effectiveness. Br J Rheumatol 1998;37:546-54.

6. Roddy E, Zhang W, Doherty M. Aerobic walking or strengthening exercise for osteoarthritis of the knee? A systematic review. Ann Rheum Dis 2005;64:544-8.

7. Roddy E, Zhang W, Doherty M, et al. Evidence-based recommendations for the role of exercise in the management of osteoarthritis of the hip or knee-the MOVE consensus. Rheumatol 2005;44:67-73.

8. National Center for Complementary and Alternative Medicine. Tai chi for health purposes. http://nccam.nih.gov/health/taichi/ (accessed 14 Feb 2011).

9. Lee MS, Pittler MH, Ernst E. Tai chi for osteoarthritis: a systematic review. Clin Rheumatol 2008;27:211-18.

10. Hall A, Maher C, Latimer J, et al. The effectiveness of Tai Chi for chronic musculoskeletal pain conditions: a systematic review and meta-analysis. Arthritis Rheum 2009;61:717-24.

11. Ni GX, Song L, Yu B, et al. Tai Chi improves physical function in older Chinese women with knee osteoarthritis. J Clin Rheumatol 2010;16:1-4.

12. Brismee JM, Paige RL, Chyu MC, et al. Group and home-based tai chi in elderly subjects with knee osteoarthritis: a randomized controlled trial. Clin Rehabil 2007;21:99-111.

13. Wang $\mathrm{C}$, Schmid $\mathrm{CH}$, Hibberd PL, et al. Tai Chi is effective in treating knee osteoarthritis: a randomized controlled trial. Arthritis Rheum 2009;61:1545-53.
14. Lee HJ, Park HJ, Chae Y, et al. Tai Chi Qigong for the quality of life of patients with knee osteoarthritis: a pilot, randomized, waiting list controlled trial. Clin Rehabil 2009;23:504-11.

15. Song $R$, Lee EO, Lam $P$, et al. Effects of tai chi exercise on pain, balance, muscle strength, and perceived difficulties in physical functioning in older women with osteoarthritis: a randomized clinical trial. J Rheumatol 2003;30:2039-44.

16. Song R, Eom A, Lee E, et al. Effects of tai chi combined with self-help program on arthritic symptoms and fear of falling in women with osteoarthritis. J Muscle Joint Health 2009;16:46-54.

17. Fransen M, Nairn L, Winstanley J, et al. Physical activity for osteoarthritis management: a randomized controlled clinical trial evaluating hydrotherapy or tai chi classes. Arthritis Rheum 2007;57:407-14.

18. Hartman CA, Manos TM, Winter C, et al. Effects of T'ai Chi training on function and quality of life indicators in older adults with osteoarthritis. J Am Geriatrics Soc 2000;48:1553-9.

19. Adler PA. The Effects of Tai Chi on Pain and Function in Older Adults with Osteoarthritis [RCT-included]. Case Western Reserve University, 2007.

20. Higgins JPT, Douglas GA. Assessing risk of bias in included studies In: Julian PTH, Green S, eds. Cochrane Handbook for Systematic Reviews of Interventions. Chichester, UK: Wiley-Blackwell, 2008:187-241.

21. Follmann D, Elliott P, Suh I, et al. Variance imputation for overviews of clinical trials with continuous response. J Clin Epidemiol 1992;45:769-73.

22. Higgins JPT, Deeks JJ, Douglas GA. Special topics in statistics. In: Julian PTH, Green S, eds. Cochrane Handbook for Systematic Reviews of Interventions. Chichester, UK: Wiley-Blackwell, 2008:481-529.

23. Borenstein M, Hedges LV, Higgins JPT, et al, eds. Meta-Regression Chichester, UK: John Wiley, 2009:187-203.

24. Sterne JAC, Egger M, Moher D. Addressing reporting biases. In: Julian PTH, Green S, eds. Cochrane Handbook for Systematic Reviews of Interventions. Chichester, UK: Wiley-Blackwell, 2008:297-333.

25. Egger M, Smith GD. Bias in location and selection of studies. BMJ 1998;316:61-6.

26. Ernst E, Pittler MH. Alternative therapy bias. Nature 1997;385:480.

27. Rothstein HR, Sutton AJ, Borenstein M. Publication bias in metaanalysis. In: Rothstein HR, Sutton AJ, Borenstein M, eds. Publication Bias in Meta-Analysis. Chichester, UK: Wiley, 2005:1-7.

28. Vickers A, Goyal N, Harland R, et al. Do certain countries produce only positive results? A systematic review of controlled trials. Contro Clin Trials 1998;19:159-66.

29. Pildal J, Hrobjartsson A, Jorgensen $\mathrm{KJ}$, et al. Impact of allocation concealment on conclusions drawn from meta-analyses of randomized trials. Int J Epidemiol 2007;36:847-57.

30. Schulz KF, Chalmers I, Hayes RJ, et al. Empirical evidence of bias. Dimensions of methodological quality associated with estimates of treatment effects in controlled trials. JAMA 1995;273:408-12.

31. Juni $P$, Witschi $A$, Bloch $R$, et al. The hazards of scoring the quality of clinical trials for meta-analysis. JAMA 1999;282:1054-60.

32. Moher D, Jadad AR, Nichol G, et al. Assessing the quality of randomized controlled trials: an annotated bibliography of scales and checklists. Control Clin Trials 1995;16:62-73.

33. Hartling L, Ospina M, Liang $\mathrm{Y}$, et al. Risk of bias versus quality assessment of randomised controlled trials: cross sectional study. BMJ 2009;339:b4012.

34. Armijo-Olivo S, Stiles CR, Hagen NA, et al. Assessment of study quality for systematic reviews: a comparison of the Cochrane Collaboration Risk of Bias Tool and the Effective Public Health Practice Project Quality Assessment Tool: methodological research. J Eval Clin Pract. Published Online First: 3 August 2010. doi:10.1111/ j.1365-2753.2010.01516.x

35. Audette JF. Tai chi in pain medicine. In: Audette JF, Bailey A, eds. Integrative Pain Medicine. Totowa, NJ: Humana Press, 2008:243-58.

36. Burks K. Osteoarthritis in older adults: current treatments. J Geronto Nurs 2005;31:11.

37. Yocum DE, Castro WL, Cornett M. Exercise, education, and behavioral modification as alternative therapy for pain and stress in rheumatic disease. Rheum Dis Clin North Am 2000;26:145-59, $x-x i$

38. Wayne PM, Kaptchuk TJ. Challenges inherent to t'ai chi research: part II-defining the intervention and optimal study design. J Altern Complement Med 2008;14:191-7.

39. Wayne PM, Kaptchuk TJ. Challenges inherent to t'ai chi research: part I-t'ai chi as a complex multicomponent intervention. J Altern Complement Med 2008;14:95-102. 